\title{
Article
}

\section{The weirdness of having a bunch of other minds like yours in the room: The lived experiences of mentalization-based therapy for borderline personality disorder}

Gardner, Kathryn Jane, Elliott, Alison, Wright, Karen Margaret, Graham, Simon and Fonagy, Peter

Available at https://clok.uclan.ac.uk/28862/

Gardner, Kathryn Jane orcid iconORCID: 0000-0003-3904-1638, Elliott, Alison, Wright, Karen Margaret orcid iconORCID: 0000-0003-0693-7294, Graham, Simon and Fonagy, Peter (2019) The weirdness of having a bunch of other minds like yours in the room: The lived experiences of mentalization-based therapy for borderline personality disorder. Psychology and Psychotherapy: Theory, Research and Practice, 93 (3). ISSN 1476-0835

It is advisable to refer to the publisher's version if you intend to cite from the work. http://dx.doi.org/10.1111/papt.12243

For more information about UCLan's research in this area go to http://www.uclan.ac.uk/researchgroups/ and search for <name of research Group>.

For information about Research generally at UCLan please go to http://www.uclan.ac.uk/research/

All outputs in CLoK are protected by Intellectual Property Rights law, including Copyright law. Copyright, IPR and Moral Rights for the works on this site are retained by the individual authors and/or other copyright owners. Terms and conditions for use of this material are defined in the policies page. 
Running head: Experiences of MBT for BPD

The weirdness of having a bunch of other minds like yours in the room: the lived experiences of mentalisation-based therapy for borderline personality disorder

Kathryn J. Gardner*1, Karen M. Wright ${ }^{2}$, Alison Elliott ${ }^{2}$, Simon Graham ${ }^{3}$, \& Peter Fonagy ${ }^{4}$

${ }^{* 1}$ Corresponding author. Kathryn Jane Gardner. School of Psychology, University of Central Lancashire, Preston, Lancashire, PR1 2HE, UK.

${ }^{* 2}$ School of Nursing, University of Central Lancashire, Preston, Lancashire, PR1 2HE, UK. ${ }^{3}$ Psychotherapy and Personality Disorder Hub, Spring House, 12 Haigh Road, Waterloo, Liverpool, L22 3XP.

${ }^{4}$ Psychoanalysis Unit, Research Department of Clinical, Educational and Health Psychology University College London, Gower Street, London, WC1E 6BT.

\section{Keywords}

Borderline personality disorder; mentalisation-based therapy; change; interpretative phenomenological analysis

\section{Acknowledgements}

The authors would like to thank the four NHS trusts involved in the research, and Emma Hickey, Adam Dierckx, Sean Taylor for supporting the project and helping to recruit participants. We would also like to thank the service users and therapists who gave their time to share their experiences of MBT. 


\begin{abstract}
Objectives: Studies of lived experiences are important for improving treatment effectiveness, but most studies of mentalisation-based therapy (MBT) are quantitative. This qualitative study aimed to better understand service users' lived experiences of MBT, including their experiences of change.
\end{abstract}

Design: This is a qualitative study that used one-to-one semi-structured interviews.

Method: Semi-structured interviews were conducted with eight MBT service users recruited via four NHS trusts. Interviews were analysed using interpretative phenomenological analysis (IPA).

Results: Three superordinate themes were identified: being borderline, being in the group, and being on a journey. 'Experiences of diagnosis' and 'the group' are salient topics in the lived experiences of service users' during the MBT journey, as is the nature/type of 'change' which can create symptom reduction albeit alongside a negative felt experience.

Conclusion: Our research aligns with current thought regarding the complexity and challenges of treating BPD via psychotherapy and adds a further dimension, that of experiencing MBT and changes during therapy. The participants' experiences of BPD, and of experiencing MBT are discussed.

\title{
Practitioner Points
}

We recommend the following:

1. therapists are observant of how each client gives meaning to their experience of diagnosis, the group, and change, particularly since the experience of recovery is not all positive.

2. service users' emerging and ongoing construction of their experience of diagnosis is closely monitored and additional appropriate strategies implemented where necessary. 
Running head: Experiences of MBT for BPD

3. the impact of joining MBT, especially the group, becomes a process for formal regular review.

4. therapists undertake an in-depth exploration of service users' felt experiences to capture less quantifiable dimensions of change. 
Running head: Experiences of MBT for BPD

The weirdness of having a bunch of other minds like yours in the room: the lived experiences of mentalisation-based therapy for borderline personality disorder

Mentalisation-based therapy (MBT) is a highly structured manualized therapy that was designed to treat the difficulties associated with borderline personality disorder (BPD). MBT works within the context of attachment to improve individuals' ability to understand their own and others' intentional mental states, and subsequently improve their interpersonal and affective difficulties (Bateman \& Fonagy, 2009). Dysfunction of the attachment system is loosely coupled with the mentalisation system such that the degree of disorganization of attachment relationships should correlate with poor mentalisation problems (Fonagy \& Bateman, 2006). As individuals with experience of BPD are characterized by insecure attachments (e.g., Barone, 2003), one goal of MBT is therefore to move the service user closer to a pattern of arousal within the attachment system that is closer to that characteristic of a secure attachment (Fonagy \& Bateman, 2006).Ultimately, improvements in mentalising fosters the development of stable internal representations and increases emotional stability in BPD (Bateman \& Fonagy, 2003).

Empirical evidence for the effectiveness of MBT for treating BPD is accumulating. A recent systematic review of 14 studies concluded that MBT leads to significant reductions in self-reported symptom distress (e.g., BPD features, anxiety, and depression), suicide attempts and self-harm (Vogt \& Norman, 2018). A handful of these studies reviewed were randomized controlled trials (RCTs: Bateman \& Fonagy, 1999, 2001, 2008, 2009; Rossouw \& Fongay, 2012) where MBT was compared with treatments such as structured clinical management (rather than dialectical behavior therapy which is also highly effective in reducing BPD related symptoms: Bloom, Woodward, Susmaras, \& Pantalone, 2012).

Randomized controlled trials are the 'gold standard' in terms of evidence-based practice and demonstrating the link between treatment and good outcome; however, they are 
restricted through their use of a small set of predetermined measures of change and outcome that focus typically on increases (or decreases) in symptom reduction, placing less emphasis on changes in less quantifiable dimensions such as self-concept (Connolly \& Strupp, 1996) or felt experience. Qualitative studies are a necessary complement to RCTs and can help capture a broader range of less quantifiable symptoms and behaviours that represent client change (e.g., changes in service users' experiences, values or meanings) which may be modified or substituted with new meanings or experiences (Nilsson, Svensson, Sandell \& Clinton, 2007). Studies of lived experiences are especially useful for understanding what really matters to participants and obtaining the individuals' unique perspective of change, thus shifting the focus from researchers' preconceived and theoretically aligned ideas to the individual's construction of what they believe to be their experience. Psychotherapy researchers have long argued for the explicit utilisation of the client's frame of reference as one of several approaches for understanding perspective and experience of therapy and its efficacy (e.g., Duncan \& Monyhan, 1994; Elliot, 2010; Elliot \& James, 1989).

To the best of our knowledge there exist three published qualitative studies that have explored service users' experiences of MBT. Ó Lonargáin, Hodge and Line (2017) used interpretative phenomenological analysis (IPA) to explore general experiences of intensive outpatient MBT in service users with difficulties associated with personality disorder; participants report experiencing the group therapy sessions as challenging and unpredictable, but also describe experiencing positive change through MBT in response to events, people, and the therapy (Ó Lonargáin et al., 2017). Participants’ narrative draw also on common factors (see Hubble, Duncan \& Miller, 1999, for review) such as therapist factors (e.g., empathy) and relational processes (e.g., development of mutual trust as part of the therapeutic alliance). 
Running head: Experiences of MBT for BPD

In another study Johnson et al. (2016) used thematic analysis to explore the lived experiences of three ex-service users after MBT. Participants reported improved mentalising, consistent with the goals of MBT, but also reported a range of other ways in which they had changed: reduced self-harm and maladaptive coping behaviours, less self-hatred, and improved interpersonal relationships and social functioning. It appeared also that mutual trust and shared and understood experiences within group therapy were potential mechanisms through which participants felt able to explore wider social contexts. These findings were mostly mirrored by Dyson and Brown (2016) who used IPA to explore general experiences of MBT with a sample of six female service users with a BPD diagnosis; although, in this study the utility of shared experiences within group therapy seemed tempered by the loss of individuality, and identification with the group was necessary for participants to change and feel "cured". This notion of identification with the group fell within one of three subthemes "we are one (but not together)" - identified by Dyson and Brown (2016) and encapsulates the shared experiences of the group. The remaining two subthemes were "I'm much better now [Laugh] Hopefully?" and "You've got to be ready for therapy...You've got to be able to change" and reflect the sense that participants felt better but not cured, and that one must be willing to change, respectively. Thus, cutting across all three subthemes was the notion of 'change'. Yet, whilst these findings are a useful advancement to our understanding of general MBT experiences and of change, specific interview questions about change were not used to encourage participants' in-depth exploration of change. Participants may have varied experiences regarding what exactly they feel has changed (in a quantitative study the researcher would measure only what they believe could change i.e., the 'outcomes'), as well as varied perceptions and experiences of how they believe these changes came about (or in quantitative terms, the 'mechanisms of change' which again would be determined by the researcher). The present study fills this important gap through exploring how service users 
Running head: Experiences of MBT for BPD

make sense of their journey through therapy and advances our limited understanding of the more general lived experiences of MBT in individuals with BPD (a further paper, in production, reports on the therapist's experience of MBT). Eliciting service users' experience of the treatment is very much core to the inquisitive stance of MBT and its focus on elaborating the phenomenal experience of the individual to improve capacity for regulating emotions and behavior.

\section{Methods}

\section{Recruitment and Sample}

Service user participants were recruited over a period of seven months from different outpatient MBT programmes within four NHS trusts in the UK using purposeful sampling. The inclusion criteria were: 1) over age 18 years, and 2) undergoing outpatient MBT for difficulties associated with borderline personality disorder, facilitated by an NHS trust for at least between 6 but ideally 9 months, or who have completed at least 6 months of MBT within the last 12 months ( 6 months was deemed to be the minimum time-frame to be able to discuss aspects that may have changed during the process of MBT).

Service users meeting the inclusion criteria were sent recruitment packs by each service's administrative team and interested participants could opt into the research by contacting the relevant service by telephone, email, or post. As this resulted in poor engagement in the research in the form of low uptake, a more direct method was used whereby the chief investigator made themselves available - in a room within the service to coincide with the end of an MBT group therapy session - to speak to potential eligible participants who may wish to obtain further information about participation in the study.

All service users took part in a one-to-one interview only. In total eight participants took part, which is an acceptable sample size for an IPA study given the aim of achieving an 
'in-depth' understanding of how individuals make sense of their experiences (Smith, Flowers \& Larkin, 2009). The demographic features of the service users are shown in Table 1.

\section{INSERT TABLE 1 HERE}

\section{Ethics}

Ethical approval was obtained from the School of Psychology and Social Work Ethics Committee at the University of the first author, and from the NHS Research Ethics Committee and research and development departments of the four NHS Trusts. After reviewing detailed information about the study, all participants provided written informed consent prior to participating. All interviews were stored anonymously with a participant number and using pseudonyms, and respondents were reassured about confidentiality.

\section{Interviews}

Semi-structured one-to-one interviews were conducted with all eight service users, each lasting approximately an hour. All interviews groups took place in a pre-booked room within the NHS Trust premises and were digitally recorded. A topic guide with open-ended questions was used to promote a natural flow of conversation and to allow participants to voice their lived experience as an MBT service user. The topic guide focused discussion on participants' experiences of therapy, changes during, and/or after completing therapy if applicable, and factors that were helpful (or unhelpful) in helping them change (e.g., "how were you and your symptoms before treatment, and how are they now?", “in general, what do you attribute these various changes to?").

\section{Analysis}


Analysis of responses to the semi-structured questions was conducted using IPA and followed the guidelines in Smith et al., (2009). IPA was chosen with a view to placing the individual participant, their attitudes and beliefs, at the centre of the analysis (Shaw, 2001).

Transcripts were individually analysed, and a selection analysed and coded by the first three authors. The three authors then then came together to discuss, debate and agree codes and emergent superordinate and subordinate themes. The authors had either extensive experience of working with individuals with personality disorder and/or research expertise in the field. Potential bias was discussed to ensure that codes stayed true to participants' stories and the data, and not as fitting into the researchers' own bias or existing theory. This process ensured the credibility and trustworthiness of the data.

\section{Results}

This paper reports on all three superordinate themes, of which experience of change was one of them. Themes presented are in chronological order i.e. the order in which participants' described these experiences and each theme captures the experiences of all service users. Samples of direct quotations are used to illustrate each theme (linked to interviewees by pseudonym). We acknowledge that the labels given to some of these themes are controversial, but these reflect participants' own views (rather than our own) and uses their own words for the description of their experiences. Table 2 displays the superordinate and subthemes.

INSERT TABLE 2 HERE

\section{Being "Borderline"}

This overarching theme represents participants' attempts to make sense of their diagnosis and traits within the context of the therapy. All but one participant referred to their BPD diagnosis. Most stated that they found receiving their diagnosis at the beginning of 
MBT helpful in some way, and the overall experience appeared to be a positive one. Sally (p.29) and Lucy (p.23) both said that diagnosis was “.... relief” and Sally also said “...I feel good for having a label” (p.29). Conversely, Lucy’s sense of relief was juxtaposed with a sense of discomfort that “...personality disorder, makes you feel like you've got a shit personality." (p.32). Several participants appeared also to identify with and take ownership of their diagnosis. For example, Belinda stated “...then I just became, I don't know whatever a borderline is when you're not being medicated..." (p. 12), and attributed her BPD traits to her parents, stating that "...we are what happens when people who shouldn't have children have children." (p.28); in this sense Belinda appears to almost see herself as a product of an unfortunate event.

Several participants identified with language that is often used by others to describe associated BPD traits, such as "black and white” (Jenny, p.4), "all-or-nothing” (Sally, p.21) and “...don't touch me, hold me close.” (Sally, p.9); and made reference to “...my borderline..." (Charlotte, p.10) diagnosis to explain and understand something about themselves. There was a sense that they had learnt something about BPD, especially for Jenny who stated just that (p.4). For Amy, there was also a belief that “...there's no cure for it...” (p.24), and Katy expressed a similar sense of hopelessness as she referred to herself as “...a lost cause...." and “...unfixable..." (p.9).” (Sally, p.21) and “...don’t touch me, hold me close.” (Sally, p.9); this latter phrase perhaps reflects Sally's understanding of her relationships with others.

In addition to learning the language of "BPD", several participants appeared to have adopted the language of therapy, mechanically repeating MBT terminology and other commonly used terms in psychotherapy. For example, Charlotte stated “...because when you start mentalising you erm, you are not, because ruminating is a sign of not mentalising..." (p.13), and Belinda described her personality as “... fragmented, disintegrated...” (p.17). At 
times, there was a sense that participants were merely doing rather than being in therapy, but in other cases the context suggested that participants understood the terminology and had learnt something about themselves and their relationships. For example, Amy talked about "validation" (p.38), and Charlotte talked about "transference".

Charlotte was not the only participant to make reference to her therapist; almost all participants spoke of the importance of the therapeutic relationship, in relation to the therapists delivering the individual as well as group sessions. There were clear similarities in participants' narratives regarding the importance of therapist qualities such empathy, stability, consistency and trust.

Individual therapists were not criticised. In fact, Sally's preference for the group therapy sessions suggests a reluctance to criticise her individual therapist: "...nothing against $\mathrm{X}$ but the group therapy was the most helpful because I see things from other perspectives and...” (p.10). One exception was Amy who described a potential rupture in her friend's therapeutic relationship, but again the focus here shifted to the group because this perceived breaking of trust (due to safeguarding concerns) was brought to the group and led to feelings of anger and a lack of safety amongst group members.

\section{Being in the Group}

The third overarching theme represents service users' experience of and attempts to make sense of the group. All participants talked about learning how to be in the group, particularly in terms of feeling able to speak within a safe and trusting environment and a sense of connection with others. Disruptions to this caused by changes in group dynamics were either explicit or implicit within the narratives of approximately half of the participants.

The impact of the group was described in both positive and negative terms. For example, Amy alludes to the mentally and physically draining nature of the group: "The days when I had...therapy, the rest of the day was a write off." (p.46), whilst Lucy described how 
"...we used to go half hour early and chat..." (p.64). Yet, for some participants there was an explicit acknowledgement of highs and lows of group therapy: “...none of us wanted [it] to end..." (p.26)...the group therapy was absolutely horrendous...I just came out of there in bits, we all did." (Sally, p.17-18). Sally's view of the group as being a 'necessary evil' was inherent within all participants' narratives, but was not always explicitly stated. For Jenny however, this paradoxical state of mind was obvious as the value in terms of learning and insight was juxtaposed with the negative emotional impact of the group: "The group...gives you a different perspective...I genuinely hated it." (p.11-12).

All participants' narratives emphasised the utility of the group in terms of the power of shared experiences and/or learning gained from being with other borderline women. Hearing others talk of experiences of abuse led to moments of realisation, transitioning from a state of denial. Understanding alternative perspectives appeared to reduce isolation or provide a sense of relief. Belinda found listening to others' talk about their abusive relationships to be "distressing" (p.4) and describes also how MBT is not ameliorating the pain of her abuse (p.22). However, even for Belinda the utility of the group and the presence of other women with similar experiences and traits was clear: "...nobody else thinks like you...it's the weirdness of having a bunch of other minds like yours in the room which I can feel quite distinctly." (p.3). This normalising yet paradoxical experience was also described by Lucy, although unlike Belinda and Amy the importance of being with other like-minded "women" was implied rather than explicitly stated.

Finally, the experience of time, or lack thereof, was discussed by the majority of the participants. For most there seemed to be an awareness that there simply was not enough time for each person to explore their issues in any depth, and for half of the participants this led to feelings of frustration and rejection by the group therapist. Charlotte, however, valued her 
Running head: Experiences of MBT for BPD

group therapist the most: “...the group therapist is really, really good and...sort of like at the top of [their] game sort of thing..." (p.24).

\section{Being on a Journey}

This theme encapsulates the participants' journey through MBT and experiences of the point and nature of change. All participants believed they had changed, although there was variation regarding the nature of the journey and their experiences of how they had changed. For most, the journey through MBT was by all accounts an instrumental rollercoaster characterised by periods of stability which were succeeded by acceleration to more challenging and difficult times. Yet, this experience was not shared by all: the journey for Amy and Belinda was a relatively steady ride, and they did not expect it to be any other way.

With regards to more general expectations and hopes for MBT, these were varied and ranged from the broad (e.g., expectations about the nature of MBT) to the specific (i.e., expectations about how MBT would help in terms of symptom reduction); and low to high expectations. In some cases, low expectations and hopes seemed tied to participants' diagnosis and sense of despair around being unfixable: "I didn't have any expectations whatsoever...I was a lost cause...I could not see how anybody could help me.” (Katy, p.1). For Sally and Katy, MBT was very much a "last chance saloon”. Jenny and Amy were also sceptical and seemed to have no expectations. Amy viewed MBT as “...just another bloody talking therapy." (p.9), but after meeting the other group members, there seemed to be a shift in Amy's hopes for the therapy because she had “...people to relate to.” (p.9). These low expectations meant that for Amy, her expectations were exceeded when she started to see positive changes during therapy. Conversely, Carol had very high hopes for MBT:

“...possibly life changing... a lot of my issues would be dealt with.” (p. 4), and Sally said she 
Running head: Experiences of MBT for BPD

came to MBT “...completely open-minded...” (p.5) and “...was optimistic because it was something different...” (p.6).

There were contradictions within some participants' narratives. Charlotte stated that she had only vague expectations about the nature of the therapy itself, rather than any thoughts around whether MBT would help, but later describes thinking “...like why aren't you fixing it.” (p.16). During therapy, there was a clear transition for Charlotte to accepting responsibility for change and "...mentalising over it rather than hoping that they just wave the magic wand." (p.16).

Symptom reduction as a marker of recovery and/or change catalyst was discussed by all participants. Specific behavioural (e.g., reduced self-harm and substance abuse), affective (e.g., less depressed/angry/impulsive, calmer), cognitive (e.g., less distracted, improved understanding of self, better mentalising) and/or interpersonal (e.g., improved relationships with others) changes were discussed by most participants. Katy describes how pre and posttherapy she was "Two different people" (p.4). Changes to felt experience were discussed by participants in terms of good days, but for participants such as Carol and Amy their experiences appeared relatively unchanged on the bad days. Amy further described how she no longer acts on her feelings and thoughts and describes how she copes only when her "...stress levels are low..." (p.16). Amy’s description of her recovery was very much black and white and captures the dichotomy of suicide versus optimism: "...I want to rub myself out...just not exist... It's still a feeling I get now...I enjoy parts of my life more now." (p.37). Whilst experiences of symptom reduction and improved relationships were prominent, half of the participants explicitly described how their changes transferred outside of the therapeutic setting to relationships and other aspects of the real world. For these participants the learning and application of MBT skills to other relationships and life challenges was obvious. In spite of this, Amy still separated some of her learning from the 
outside world (“...can't really function in society as a, a normal person..." p.42). This sense of separation was made explicit by Belinda, whose reference to “...the outside world..." focused on the fact that people have "...their own agenda..." (p.22).

\section{Discussion}

This study extends existing knowledge about the lived experiences of service users who are undergoing or have undergone intensive outpatient mentalisation based therapy in the UK. Whilst we directly enquired about change and therefore fill an important gap in the literature here, change was only one of three overarching themes. We obtained a broader perspective of themes previously identified in other studies (e.g., Dyson \& Brown, 2016): experiences of BPD diagnosis and behaviours, and experiences of the group component of MBT.

The initial phase of MBT within these services includes giving the diagnosis (in a mentalising way), providing psychoeducation, and explaining the approach to treatment (Bateman \& Fonagy, 2006). Whilst diagnosis is not a focal part of MBT, participants' narratives focused heavily on attempts to make sense of their diagnosis and MBT terminology appeared to be inextricably woven into some participants' everyday language. Consistent with Dyson and Brown (2016) the deep understanding of MBT terms was lacking and the transcripts suggested that whilst some participants were "being borderlines" they were "doing" and not "being" in therapy. The confusion in terminology is not surprising, and the severance between inner and outer reality, to some extent, suggests that participants were in "pretend mode" (Bateman \& Fonagy, 2006) with poor mentalising around the diagnosis issue.

Yet, the experiential impact of diagnosis, whilst powerful, was not the same for all participants. A minority described internally conflicted experiences (e.g., relief vs discomfort) and thus a conflicted relationship to diagnosis. Thus, whilst some service users 
may dislike the negative aspects of being labelled, they can nonetheless identify with the clinical criteria buried within the description of the diagnosis. For others, the BPD diagnosis engendered either a sense of hope or despair, consistent with previous IPA studies on service users' general experiences of having ones' difficulties and behaviours described and understood within the context of this diagnosis (Horn, Johnstone \& Brooke, 2007). These varied experiences reinforce the notion that there is no one truth to the way diagnosis is experienced by different people.

A sense of being incurable was a view expressed by participants in Dyson and Brown's (2016) study and which is in stark contrast to Bohart's (2000) model that sees the client as an active self-healer and the most crucial common factor in psychotherapy who is "aided and abetted by the therapist" (p. 130). Fundamentally, being "incurable" reflects an inaccurate and pessimistic view of a 'somewhat' biologically-based diagnosis, which in essence affects the very core of the self. This pathologising rather than normalising experience of diagnosis, which may or may not have been socially constructed, is important to understand because it can negatively impact on hope and recovery (Walker, 2006). "Hope", or lack therefore, is a common therapy factor (i.e., a common core ingredient across all therapies) and can contribute more variance in therapeutic outcome than specific treatment effects (Duncan, 2014). The majority in this study felt hopeful about MBT and change and this was not always tied explicitly to a positive experience of diagnosis. This is important because clients who feel hopeful about their recovery may be more actively involved in contributing to the therapeutic outcome. The client's active participation in therapy is one of the most important common factors predicting successful outcome (Orlinsky, Rnnestad, \& Willutzki, 2004).

Participants varied experiences may reflect a range of factors, including client (e.g., self-concept: Vater, Schroder-Abe, Weißgerber, Roepke \& Schütz, 2015; self-stigma: Rüsch., 
Running head: Experiences of MBT for BPD

et al., 2006), and relational and therapist factors (e.g., aspects of the therapeutic alliance, the ability of the therapist to cultivate client hope, therapist's interpersonal skills and reactivity: Aviram, Brodsky, \& Stanley, 2006; Grencavage \& Norcross, 1990; Wampold, 2015). A positive therapeutic relationship was valued by almost all participants and it is conceivable that this was a catalyst for change, although it was not explicitly referred to as such. The therapeutic relationship is also a common psychotherapy factor that may contribute to outcome (see Hubble, Duncan \& Miller, 1999, for review), and has been identified as important in previous studies of service users’ experiences of MBT (Ó Lonargáin et al., 2017). Participants' experiences of "trust" with their therapist echo previous findings (Johnson et al., 2016; Ó Lonargáin et al., 2017) and might serve as an example of what Fonagy and Allison (2014) term "epistemic trust": that the individual learns to trust what is provided by others (e.g., alternative perspectives) and which is achieved through mentalising. For some participants their therapist/s were change agents but there were "a number of dogs that did not bark", that is, some participants failed to foreground in their reports the importance of trust within the context of the therapeutic relationship. Rather, participants' narratives were focused more heavily on making sense of the group (a model factor) rather than the therapeutic relationship. The therapeutic alliance typically explains more variance in outcome than do model factors (Duncan, 2014), and one might therefore have expected greater prominence of the therapist as change agents in the narratives. Although, the centrality of the group experience is not unusual and the therapeutic approach may have primed the individual somewhat more than other approaches to reflect on the experience of being part of a treatment group.

The recognition of shared experiences with group members engendered a sense of normality, belonging and connectedness, which in his seminal work Yalom (1995) described as "universality" and "cohesiveness", respectively (these are just two of Yallom's eleven 
Running head: Experiences of MBT for BPD

therapeutic factors in group therapy that can affect outcome). Yet, because BPD is essentially a difficulty relating to others, it stands to reason that the groups are more challenging and perhaps tolerable whilst the individual therapy sessions provide a more containing experience.

The emotive and disruptive elements of the group could be interpreted in line with the 'anti-group' concept which challenges the utility of group therapy (Nitsun, 2000). Alternatively, and this is the view taken here, the group is a challenging but essential component to MBT that reflects the difficulties these individuals have in maintaining relationships with others. This combination of group with individual therapy is common to other effective treatments of BPD such as Dialectical Behaviour Therapy (Linehan, 1993).

Whilst the group component was a major theme and of great importance to participants in this study (the therapeutic relationship was one subtheme subsumed within the superordinate BPD diagnosis theme), the impact of the group was described in both positive and negative terms. Indeed, group therapy was a source of strain and was interpersonally and emotionally challenging, consistent with previous MBT studies (Dyson \& Brown, 2016; Ó Lonargáin et al., 2017) and the wider literature (e.g., Hodgetts, Wright \& Gough, 2007). Yet, the amorphous identity and heterogenous personality that typifies individuals with BPD was seemingly no longer problematic, as individuals instead identified with and found comfort in the shared experiences of their all-female group. Being in the group met a need for secure attachment to others, be it therapist or fellow group member, despite an apparent 'dance' between a sense of despair and normality. Fundamentally, the group was a practice ground where participants' problems could 'come to life' when with others in the group, thus allowing therapy to focus on the issues most salient to each other and to the group. The limited time for each group (or practice) session was perceived negatively by participants, but 
there was no awareness that this was perhaps because they were forced to manage the feeling of being denied.

Experiences of diagnosis and the group encapsulate only specific aspects of the therapeutic journey. Journey signifies 'change' which was usually described as either a gradual process reflecting the passage of time after so long in therapy, or as fleeting individualised moments of change throughout the course of therapy ('lightbulb' moments). Randomised control trials with outcomes measures at multiple time points during therapy (e.g., Rossouw \& Fongay, 2012) fail to capture the nuances of such experiences. Still, participants' collective experience of change was very much consistent with RCT results that have demonstrated the positive impact of MBT on mentalisation and BPD symptomology (e.g., Bateman \& Fonagy, 1999, 2008; Rossouw \& Fongay, 2012).

Participants experienced changes in other areas consonant with the theoretical principals of MBT, such as better emotion dysregulation, improved relationships, and greater impulse control. However, experiences of change also included less quantifiable dimensions. Consistent with previous research, the felt experience associated with BPD seemed somewhat impervious to change and for some individuals was still poor, even though impulsive behaviours such as self-harm and suicidal acts appeared to have reduced (Dyson \& Brown, 2016). By all accounts these individuals had improved, and an RCT that operationalises success as reduced self-harm/suicidal acts would probably conclude the same. However, by failing to operationalise felt experience RCTs do not capture fully the extent nor nature of recovery that has been captured here.

The changes noted by participants clearly extended beyond the therapeutic setting. Indeed, improved skills and social connections were noted by many. Given though, the aims of MBT, one would have expected more explicit and elaborate discussions regarding changes 
Running head: Experiences of MBT for BPD

(for better or worse) in the interpersonal relationships of the participants external to the therapy.

\section{Clinical and Research Implications}

Each theme has clinical implications. First, service users' emerging and ongoing construction of their experience of diagnosis should be closely monitored and additional supportive strategies implemented where necessary. An open, sensitive, collaborative discussion of the diagnosis is a "...necessary and constructive..." initial phase in MBT (Bateman \& Fonagy, 2006, p.39), but continued dialogue around service users' own meaning of diagnosis would help therapists identify whether strategies that engender hope and stimulate personal agency are necessary. Additional training for clinicians that improves their understanding of the social construction of the BPD diagnosis (i.e., the notion that we create realities through discourse) would be fruitful.

Second, we suggest the impact of joining MBT, especially the group, becomes a process for formal regular review. Once group therapy has started, monitoring of participants' emerging experience of the therapy in real time (i.e., to elicit the fears and negative feelings generated) might provide a helpful corrective to potential missteps to the process of offering this type of treatment. The journey through MBT is difficult, especially the group where clients' difficulties come to the fore for scrutiny, and such monitoring and discussions would help these negative feelings become contained. This finding highlights also the need for further qualitative exploration of how service users' experience the common factors within MBT.

Third, we recommend in-depth exploration during therapy of felt experiences (both positive and negative) which could to all intents and purposes relate to post-traumatic growth rather than distress (Slavin-Spenny, Cohen, Oberleitner \& Lumley, 2011). Change was expressed in an experiential way and expressed in service users' own terms rather than in 
Running head: Experiences of MBT for BPD

relation to predefined categories and measures. The juxtaposition of good treatment outcomes resulting from RCTs and the remaining negative felt experience reported by service users in this study highlights also the importance of capturing client experience when assessing the effectiveness of treatments.

\section{Limitations and Future Directions}

This study used a self-selected sample and it is possible that only those service users who had made some or even significant progress in therapy chose to participate. Indeed, one service user commented that 'I wouldn't have come here today if I didn't think it'd had any effect on me but I feel so strongly about it..." (Katy, p.15). This small sample limits also the generalisability of the findings, and it is not clear if these experiences would be roughly equivalent in males given the all-female sample.

The retrospective nature of the interviews means also that potentially important information may not have been have been remembered or may have been distorted, particularly in those individuals who had completed MBT some time ago.

Finally, all participants could have made attributional errors, and service users may also not have had access to, nor been able to fully express nor articulate their traits, behaviours or experiences. Future research could address this by supplementing client experience with therapists' perspectives of the client experience and the impact of the therapy on their client, as these perceptions can differ considerably from clients' experiences (Elliot \& James, 1989). Indeed, therapists can act as observers of client experience and draw on factors such as their training, client's backgrounds, and client's nonverbal cues to help shed light on client experiences (Elliot \& James, 1989). Moreover, the perspective of the other individual within the therapeutic relationship (i.e., the therapist) is important on theoretical, empirical and practical grounds, and increased awareness of the therapists' part in the therapeutic encounter in this area could lead to recommendations which could improve how 
MBT is delivered. Future research should focus specifically on the experiences of the therapist as well as the client to better understand and nature of change during MBT.

\section{Conclusions}

Borderline Personality Disorder is a complex and troubling disorder for both service user and practitioner, with few interventions claiming any significant improvement in the quality of life of those who experience BPD. This phenomenological study considers one successful therapy, MBT, and provides valuable insight into the lived experience of having BPD whilst engaging in therapy. Participants' attempts to make sense of their diagnosis/symptoms, the utility and futility of the group, and the nature of change highlight the complexity and challenges of treating BPD via MBT. These three emergent themes: being borderline, being in the group, and being on a journey provide valuable insights which may facilitate the improvement of existing MBT programs. 


\section{References}

Aviram, R. B., Brodsky, B. S., \& Stanley, B. (2006). Borderline personality disorder, stigma, and treatment implications. Harvard Review of Psychiatry, 14(5), 249256, DOI: 10.1080/10673220600975121.

Barone, L. (2003). Developmental protective and risk factors in borderline personality disorder: a study using the adult attachment interview. Attachment \& Human Development, 5(1), 64-77. doi: $10.1080 / 1461673031000078634$

Bateman, A., \& Fonagy, P. (1999). Effectiveness of partial hospitalization in the treatment of borderline personality disorder: a randomized controlled trial. American Journal of Psychiatry, 156, 1563-1569. doi:10.1176/ajp.156.10.1563.

Bateman, A., \& Fonagy, P. (2001). Treatment of borderline personality disorder with psychoanalytically oriented partial hospitalization. American Journal of Psychiatry, 158(1), 36-42. doi:10.1176/appi.ajp.158.1.36.

Bateman, A., \& Fonagy, P (2003). The development of an attachment-based treatment programme for borderline personality disorder. Bulletin of Menninger Clinic 67(3), 187-211. doi:10.1521/bumc.67.3.187.23439.

Bateman, A., \& Fonagy, P. (2006). Mentalisation-based treatment for borderline personality disorder: a practical guide. Oxford: Oxford University Press.

Bateman, A., \& Fonagy, P. (2008). 8-year follow-up of patients treated for borderline personality disorder: mentalisation-based treatment versus treatment as usual. The American Journal of Psychiatry, 165(5), 631-638. doi:10.1176/appi.ajp.2007.07040636. 
Running head: Experiences of MBT for BPD

Bateman, A., \& Fonagy, P. (2009). Randomized controlled trial of outpatient mentalisation-based treatment versus structured clinical management for borderline personality disorder. American Journal of Psychiatry, 166(12), 1355-1364. doi:10.1176/appi.ajp.2009.09040539

Bohart, A. C. (2000). The client is the most important common factor: clients' self-healing capacities and psychotherapy. Journal of Psychotherapy Integration, 10(2), 127-149. doi:10.1023/A:1009444132104.

Bloom, J. M., Woodward, E. N., Susmaras, T., \& Pantalone, D. W. (2012). Use of dialectical behaviour therapy in inpatient treatment of borderline personality disorder: a systematic review. Psychiatric Services (Washington, D.C.), 63(9), 881-888. doi:10.1176/appi.ps.201100311.

Connolly, M., \& Strupp, H. (1996). Cluster analysis of patient reported psychotherapy outcomes. Psychotherapy Research, 6(1),30-42. doi: 10.1080/10503309612331331558.

Duncan, B. L., \& Monyhan, D.W. (1994). Applying outcome research: Intentional utilization of the client's frame of reference. Psychotherapy: Theory, Research, Practice, Training, 31(2), 294301. doi.org/10.1037/h0090215

Dyson, H., \& Brown, D. (2016). The experience of mentalisation-based treatment: An interpretative phenomenological study. Issues in Mental Health Nursing, 37(8), 586-595, doi:10.3109/01612840.2016.1155246.

Duncan, B. L. (2014). On becoming a better therapist: Evidence-based practice one client at a time (Second Edition). Washington DC: American Psychological Association.

Elliot, R. (2010). Psychotherapy change process research: Realizing the promise. Psychotherapy Research, 20 (2), 123-135. doi: 10.1080/10503300903470743. 
Running head: Experiences of MBT for BPD

Elliot, R., \& James, E (1989). Varieties of client experience in psychotherapy: An analysis of the literature. Clinical Psychology Review, 9(4), 443-467.

Fonagy, P., \& Allison, E. (2014). The role of mentalising and epistemic trust in the therapeutic relationship. Psychotherapy, 51(3), 372-380. Doi: 10.1037/a0036505.

Fonagy, P. \& Bateman, A. (2006). Mechanisms of change in mentalisation-based therapy of borderline personality disorder. Journal of Clinical Psychology, 62, 411-430.

Grencavage, L. M., \& Norcross, J. C. (1990). Where are the commonalities among the therapeutic common factors? Professional Psychology: Research and Practice, 121(5), 372-378. doi: 10.1037/0735-7028.21.5.372.

Hodgetts, A., Wright, J., \& Gough, A. Clients with borderline personality disorder: Exploring their experiences of dialectical behaviour therapy. Counselling and Psychotherapy Research, 7(3), 172-177. doi:10.1080/14733140701575036

Horn, N., Johnstone, L., \& Brooke, S. (2007). Some service user perspectives on the diagnosis of borderline personality disorder. Journal of Mental Health, 16(2), 255-269. doi:10.1080/09638230601056371.

Hubble, M., Duncan, B., \& Miller, S. (Eds.). (1999). The heart and soul of change. Washington: American Psychological Association Press.

Johnson, E.L., Mutti, M-F., Springham, S., \& Xenophontes, I. (2016). Mentalising after mentalisation based treatment. Mental Health and Social Inclusion, 20(1), 44-51. doi: 10.1108/MHSI-11-2015-0042.

Linehan, M. M. (1993). Cognitive behavioural treatment of borderline personality disorder. New York: Guilford Press. 
Running head: Experiences of MBT for BPD

Nilsson, T., Svensson, M., Sandell, R., \& Clinton, D. (2007). Patients' experiences of change in cognitive behavioral therapy and psychodynamic therapy: a qualitative comparative study. Psychotherapy Research, 17(5), 553-566. Doi: 10.1080/10503300601139988

Nitsun, M. (2000). The future of the group. International Journal of Group Psychotherapy, 504), 455-472. Doi:10.1080/00207284.2000.11491024.

Ó Lonargáin, D., Hodge, S. \& Line, R. (2017). Service user experiences of mentalisation-based treatment for borderline personality disorder. Mental Health Review Journal, 22(1), 16-27. doi:10.1108/MHRJ-04-2016-0008.

Orlinsky, D. E., Ronnestad, M. H., \& Willutzki, U. (2004). Fifty years of psychotherapy processoutcome research: Continuity and change. In M. J. Lambert (Ed.). Bergin and Garfield's Handbook of Psychotherapy and Behavior Change (5th ed., pp. 307-390). New York: Wiley.

Rossouw, T., \& Fonagy, P. (2012). Mentalisation-based treatment for self-harm in adolescents: A randomized controlled trial. Journal of the American Academy of Child and Adolescent Psychiatry, 51(12), 1304-1313.e3. doi:10.1016/j.jaac.2012.09.018.

Rüsch, N., Hölzer, A., Hermann, C., Schramm, E., Jacob, G., Bohus, M., Lieb, K., \& Corrigan, P. (2006). Self-stigma in women with borderline personality disorder and women with social phobia. The Journal of Nervous and Mental Disease, 194(10), 766-773. doi: 10.1097/01.nmd.0000239898.48701.dc.

Shaw, R. (2001). Why use interpretative phenomenological analysis in health psychology? Health Psychology Update, 10(4), 48-52.

Slavin-Spenny, O. M., Cohen, J. L., Oberleitner, L. M., \& Lumley, M. A. (2011). The effects of different methods of emotional disclosure: differentiating post-traumatic growth from stress symptoms. Journal of Clinical Psychology, 67(10), 993-1007. doi: 10.1002/jclp.20750. 
Running head: Experiences of MBT for BPD

Smith, J., Flowers, P., \& Larkin, M. (2009). Interpretative phenomenological analysis: Theory, method and research. Sage: London.

Vater, A., Schroder-Abe, A., Weißgerber, S., Roepke., S., \& Schütz, A. (2015). Self-concept structure and borderline personality disorder: evidence for negative compartmentalisation, Journal of Behavior Therapy and Experimental Psychiatry, 46, 50-58. doi: 10.1016/j.jbtep.2014.08.003.

Vogt, K. S., \& Norman, P. (2018). Is mentalisation-based therapy effective in treating the symptoms of borderline personality disorder? A systematic review. Psychology and Psychotherapy: Theory, Research and Practice. doi: 10.1111/papt.12194

Walker, M.T. (2006). The social construction of mental illness and its implications for the recovery model. International Journal of Psychosocial Rehabilitation, 10(1), 71-87.

Wampold, B. E. (2015). How important are the common factors in psychotherapy? An update. World Psychiatry 14(3), 270-277. doi: 10.1002/wps.20238.

Yalom, I. D. (1995). The theory and practice of group psychotherapy (4th ed.). New York: Basic Books. 
Running head: Experiences of MBT for BPD

Table 1

Demographic Features of Service Users

\begin{tabular}{|c|c|c|c|c|c|}
\hline Pseudonym & Age & Sex & $\begin{array}{l}\text { Years in Mental } \\
\text { Health Service }\end{array}$ & $\begin{array}{l}\text { Length of time attending } \\
\text { MBT (in months) }\end{array}$ & $\begin{array}{l}\text { Time since completed } \\
\text { MBT (if applicable) }\end{array}$ \\
\hline Katy & 44 & $\mathrm{~F}$ & 3 & 18 & 6 weeks \\
\hline Charlotte & 25 & $\mathrm{~F}$ & 8 & 11 & - \\
\hline Sally & 64 & $\mathrm{~F}$ & 38 & 18 & 9 months \\
\hline Jenny & 22 & $\mathrm{~F}$ & 6 & 12 & 2 months \\
\hline Carol & 48 & $\mathrm{~F}$ & 21 & 16 & - \\
\hline Belinda & 55 & $\mathrm{~F}$ & 24 & 10 & - \\
\hline Amy & 27 & $\mathrm{~F}$ & 12 & 11 & - \\
\hline Lucy & 48 & $\mathrm{~F}$ & 24 & 12 & 3 weeks \\
\hline
\end{tabular}


Running head: Experiences of MBT for BPD

Table 2

Superordinate and Subthemes

\section{Superordinate themes}

\section{Subthemes}

Being "Borderline"

Identifying with my BPD diagnosis and traits

My therapist and me

Learning the language of therapy

Being in the Group

The power of shared experiences

The physical and emotional impact of the group

Being with other borderlines...women only please!

Listen, talk, trust: learning how to be in the group

There's just not enough time!

The group: a necessary evil

Being on a Journey

The point and nature of change

My mode of transport: from a gentle stroll to a mental rollercoaster

My hopes and expectations: the last chance saloon!

Recovery markers and change catalysts

Learning for life/MBT and the real world

Life without MBT 